\title{
PH 10 Basic Reversed-Phase Liquid Chromatography
}

National Cancer Institute

\section{Source}

National Cancer Institute. pH 10 Basic Reversed-Phase Liquid Chromatography. NCI

Thesaurus. Code C161773.

A form of basic reversed-phase liquid chromatography where the mobile phase has a pH of 10 . 